\title{
Conyza canadensis: Green Extraction Method of Bioactive Compounds and Evaluation of Their Antifungal Activity
}

\author{
Rafael S. Porto, ${ }^{a}$ Susanne Rath ${ }^{a}$ and Sonia C. N. Queiroz ${ }^{*, b}$ \\ ${ }^{a}$ Departamento de Química Analítica, Instituto de Química, Universidade de Campinas, CP 6154, \\ 13084-971 Campinas-SP, Brazil \\ ${ }^{b}$ EMBRAPA Meio Ambiente, CP 69, 13820-000 Jaguariúna-SP, Brazil
}

\begin{abstract}
Synthetic fungicides are a common treatment for post-harvest diseases in fruits, although demand is increasing for alternatives such as biopesticides. The aim of this work was to investigate the presence of naturally occurring antifungal compounds in Brazilian specimens of the weed Conyza canadensis. Two compounds [(4Z)-lachnophyllum lactone and (4Z,8Z)-matricaria lactone] were isolated and their antifungal activities were evaluated against eight postharvest disease fungi. Aspergillus niger, Cladosporium sp., and Penicillium digitatum proved susceptible to the treatment (minimum inhibitory concentrations varying from 32 to $64 \mu \mathrm{g} \mathrm{mL}^{-1}$ ). These fungi are common postharvest pathogens of fruits and vegetables, causing rots and secreting mycotoxins. A green and sustainable extraction method employing pressurized hot water was developed and optimized $\left(100{ }^{\circ} \mathrm{C}, 4 \times 1 \mathrm{~min}\right.$ cycles). Yields of 1.46 and $0.24 \mathrm{mg} \mathrm{g}^{-1}$ were obtained for (4Z)-lachnophyllum lactone and (4Z,8Z)-matricaria lactone, respectively. The extract could be applied directly to fruits and vegetables in postharvest treatments.
\end{abstract}

Keywords: Conyza canadensis, acetylene, horseweed, antifungal, PHWE

\section{Introduction}

Postharvest diseases are the main factors responsible for fruit losses along the production chain. ${ }^{1,2}$ These diseases are usually caused by fungal pathogens that are commonly controlled by the application of synthetic fungicides. ${ }^{3}$ However, natural products, classified as biopesticides by the U.S. Environmental Protection Agency, ${ }^{4}$ are emerging as a promising alternative for crop protection. ${ }^{5}$ This is due to increasing concerns regarding the environmental impacts of synthetic pesticides, as well as stricter controls on their use and the appearance of fungicide-resistant strains. ${ }^{1,6}$

Given the importance of developing new biopesticides and investigating their spectra of action, a recent survey showed promising results with the allelopathic plant Conyza canadensis (L.) Cronquist, which belongs to the Asteraceae family and is popularly known as horseweed. ${ }^{7}$ This plant is a potential source of bioactive compounds ${ }^{8}$ and several studies have reported the fungitoxic effects of its essential oils, ${ }^{9-11}$ although the compounds responsible for such activity were not identified. Queiroz et $a .^{7}$ found three fungitoxic compounds in

*e-mail: sonia.queiroz@embrapa.br dichloromethane extracts of $C$. canadensis specimens collected in the USA: (4Z)-lachnophyllum lactone (1), (4Z,8Z)-matricaria lactone (2), and (2Z,8Z)-matricaria acid methyl ester (3), whose chemical structures are shown in Figure 1. Compounds $\mathbf{1}$ and $\mathbf{2}$ showed antifungal activity against three phytopathogenic fungi: Colletotrichum acutatum, Colletotrichum fragariae and Colletotrichum gloeosporioides. The activity of compound 3 against these fungi was reported previously. ${ }^{12}$

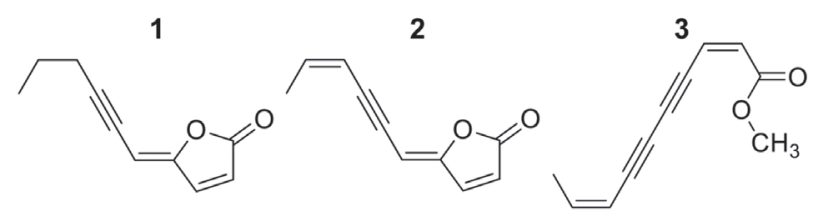

Figure 1. Chemical structures of (4Z)-lachnophyllum lactone (1), (4Z,8Z)matricaria lactone (2), and (2Z,8Z)-matricaria acid methylester (3).

The aim of this study was to investigate the presence of compounds $\mathbf{1}, \mathbf{2}$ and $\mathbf{3}$ in Brazilian specimens of $C$. canadensis and to determine their antifungal activity against eight common postharvest disease fungi. Additionally, a new extraction method was evaluated as an alternative to solvent extraction with dichloromethane. This green procedure employed pressurized hot water 
extraction (PHWE) and provided crude aqueous extracts that could be used directly in postharvest treatments.

\section{Experimental}

Instrumentation

Flash chromatography was performed using an Isolera Four system (Biotage, Uppsala, Sweden) equipped with a SNAP cartridge (KP-Sil $100 \mathrm{~g}, 39 \times 157 \mathrm{~mm}$, 45-50 $\mu \mathrm{m}$ ) and a UV detection system (254 and $280 \mathrm{~nm}$ ). ${ }^{1} \mathrm{H}$ and ${ }^{13} \mathrm{C}$ nuclear magnetic resonance (NMR) spectra, as well as ${ }^{1} \mathrm{H}-{ }^{13} \mathrm{C}$ heteronuclear single quantum coherence (HSQC) spectra, were recorded using either an AVANCE $400 \mathrm{MHz}$ spectrometer or an AVANCE $500 \mathrm{MHz}$ spectrometer (Bruker, Rheinstetten, Germany). The fractions and the purified compounds were analyzed by GC-MS using a 7890A gas chromatograph (Agilent, Santa Clara, CA) coupled to a 5975C inert XL MSD single quadrupole detector operated with $70 \mathrm{eV}$ electron ionization. An Agilent HP-5 ms capillary column ( $30 \mathrm{~m} \times 0.25 \mathrm{~mm}, 0.25 \mu \mathrm{m})$ was used. The identities of the compounds were confirmed by analysis using a GC-2010 Plus gas chromatograph (Shimadzu, Kyoto, Japan) coupled to a TQ8040a triple quadrupole detector $(70 \mathrm{eV}$ electron ionization) and equipped with a Restek Rtx-5MS capillary column $(30 \mathrm{~m} \times 0.25 \mathrm{~mm}, 0.25 \mu \mathrm{m})$. Pressurized hot water extractions were performed using a Dionex ASE 350 accelerated solvent extractor (Thermo Scientific, Waltham, MA) with $34 \mathrm{~mL}$ stainless steel sample cells and glass fiber thimbles. Quantitation of bioactive compounds in the extracts was performed by gas chromatography with flame ionization detector (GC-FID) using a 7890A gas chromatograph (Agilent, Santa Clara, CA) equipped with an HP-5 capillary column $(30 \mathrm{~m} \times 0.32 \mathrm{~mm}, 0.25 \mu \mathrm{m})$. Details of the chromatography and NMR operational conditions are provided in the Supplementary Information section.

\section{Plant material}

The aerial parts of $C$. canadensis were collected in Jaguariúna, São Paulo, Brazil (22\%43'13'"S and $46^{\circ} 01$ ' $10^{\prime \prime} \mathrm{W}$ ) in August 2013. A voucher specimen was deposited under the number 179015 at the University of Campinas Herbarium (São Paulo, Brazil).

Isolation of bioactive compounds

A $250 \mathrm{~g}$ sample of fresh aerial parts of $C$. canadensis was air-dried in a fume hood at $40{ }^{\circ} \mathrm{C}$ for one week. After grinding in a cutting mill, the material was submitted to maceration extraction with $500 \mathrm{~mL}$ of dichloromethane over three days, with solvent renewal each day, yielding $13.08 \mathrm{~g}$ of raw extract.

The dichloromethane extract was dissolved in methanol:water (90:10, v/v) and subjected to partitioning with $200 \mathrm{~mL}$ of hexane (3 times). Water was added to the remaining methanolic fraction to achieve 70:30 (v/v) methanol:water, followed by partitioning with $200 \mathrm{~mL}$ of chloroform (3 times). The chloroform fractions were combined and dried over magnesium sulfate, and the solvent was evaporated at $40{ }^{\circ} \mathrm{C}$ using a rotary evaporator. This procedure yielded $3.31 \mathrm{~g}$ of chloroform extractable.

The chloroform extract was separated by flash chromatography. Based on gas chromatography-mass spectrometry (GC-MS) analysis, six similar fractions were combined, yielding $338 \mathrm{mg}$ of compound $\mathbf{1}$. In the same way, six other fractions were combined, yielding $53 \mathrm{mg}$ of compound 2 .

Isolates

\section{(4Z)-Lachnophyllum lactone (1)}

Brownish oil (338 mg); molecular formula $\mathrm{C}_{10} \mathrm{H}_{10} \mathrm{O}_{2}$; MS/MS (EI, $70 \mathrm{eV}$ ) $\mathrm{m} / \mathrm{z}(\%) 162.0\left[\mathrm{M}^{+}\right]$(precursor ion), 147.0 (23) $\left[\mathrm{M}-\mathrm{CH}_{3}\right]^{+}, 133.0$ (25) $\left[\mathrm{M}-\mathrm{C}_{2} \mathrm{H}_{5}\right]^{+}$, 119.1 (31) $\left[\mathrm{M}-\mathrm{C}_{3} \mathrm{H}_{7}\right]^{+}, 105.1$ (14) $\left[\mathrm{M}-\mathrm{C}_{2} \mathrm{H}_{5}-\mathrm{CO}^{+}\right.$, 91.1 (47) $\left[\mathrm{M}-\mathrm{C}_{3} \mathrm{H}_{7}-\mathrm{CO}\right]^{+}, 82.0(100)\left[\mathrm{C}_{4} \mathrm{H}_{2} \mathrm{O}_{2}\right]^{+} .{ }^{1} \mathrm{H}$ and ${ }^{13} \mathrm{C}$ NMR data (Supplementary Information section) were in agreement with published values, ${ }^{13}$ except for the attributions of C-8 and C-9, as discussed.

\section{(4Z,8Z)-Matricaria lactone (2)}

Brownish oil $\left(53 \mathrm{mg}\right.$ ); molecular formula: $\mathrm{C}_{10} \mathrm{H}_{8} \mathrm{O}_{2}$; MS/MS (EI, $70 \mathrm{eV}$ ) $\mathrm{m} / z$ (\%): $160.1\left[\mathrm{M}^{+}\right]$(precursor ion), 145.0 (7) $\left[\mathrm{M}-\mathrm{CH}_{3}\right]^{+}, 131.0(100)\left[\mathrm{M}-\mathrm{C}_{2} \mathrm{H}_{5}\right]^{+}, 103.0$ (37) $\left[\mathrm{M}-\mathrm{C}_{2} \mathrm{H}_{5}-\mathrm{CO}\right]^{+}, 82.0(18)\left[\mathrm{C}_{4} \mathrm{H}_{2} \mathrm{O}_{2}\right]^{+}, 78.1$ (58) $\left[\mathrm{M}-\mathrm{C}_{4} \mathrm{H}_{2} \mathrm{O}_{2}\right]^{+}$. ${ }^{1} \mathrm{H}$ and ${ }^{13} \mathrm{C}$ NMR data (Supplementary Information section) were in agreement with published

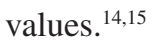

The purities of compounds $\mathbf{1}$ and $\mathbf{2}$ were confirmed by GC-MS, using area normalization, giving purities exceeding $99 \%(\mathrm{~m} / \mathrm{m})$ for both compounds. The isolated and purified compounds were used as standards for the quantitation.

\section{Standard solutions}

Stock standard solutions of compounds $\mathbf{1}$ and $\mathbf{2}$ and the internal standard coumarin (purity $\geq 99 \%$, Synth, Brazil) were prepared at $1000 \mu \mathrm{g} \mathrm{mL}^{-1}$ in ethyl acetate and stored in 
a refrigerator at $4{ }^{\circ} \mathrm{C}$ for a maximum of 30 days. Working standard solutions were prepared daily by dilutions of the stock solutions with ethyl acetate.

\section{Optimization of PHWE}

The PHWE procedure was optimized considering the following parameters: temperature (70, 90, 100, 110 and $\left.130{ }^{\circ} \mathrm{C}\right)$, time per cycle $(1,5,10,20$ and $30 \mathrm{~min})$, and number of cycles (up to four consecutive cycles). Each parameter was evaluated separately, in a univariate approach, using extractions of $5 \mathrm{~g}$ of ground plant material (aerial parts). Each extraction was carried out in duplicate. An average of $40 \mathrm{~mL}$ of aqueous extract was obtained in each procedure.

Quantitation of the bioactive compounds in the PHWE extracts

Purified extracts were prepared by partitioning $20 \mathrm{~mL}$ of the aqueous PHWE extracts with ethyl acetate $(3 \times 15 \mathrm{~mL})$ in conical tubes, with vortex agitation. The fractions were combined and the solvent was removed under vacuum in a rotary concentrator $\left(50{ }^{\circ} \mathrm{C}, 60 \mathrm{~min}, 1500 \mathrm{rpm}\right)$.

Quantitation of compounds $\mathbf{1}$ and $\mathbf{2}$ was performed by GC-FID, using coumarin ( $\left.15 \mu \mathrm{g} \mathrm{mL}^{-1}\right)$ as internal standard. The analytical curves were obtained using six concentration levels in the range $5-50 \mu \mathrm{g} \mathrm{mL}^{-1}$. The precision of the extraction procedure was assessed by analyzing the purified extracts obtained from five independent extractions carried out on the same day (intra-day) and three more extractions carried out on a second day (inter-day).

\section{Disk diffusion assays against postharvest fungi}

Isolates of Colletotrichum gloeosporioides, Alternaria alternata, Lasiodiplodia theobromae, Botryosphaeria dothidea, Aspergillus niger, Cladosporium sp., Fusarium palidoroseum and Penicillium digitatum were obtained from the Culture Collection of Microorganisms of Agricultural and Environmental Relevance (EMBRAPA Environment, Jaguariúna, São Paulo, Brazil). The species were isolated from lesions of different fruits (grapes, mangos, oranges and melons) (Table 2). The fungi were grown on potato dextrose agar (PDA) medium (HiMedia, Mumbai, India) in $9 \mathrm{~cm}$ Petri dishes, with incubation in a growth chamber at $28 \pm 2{ }^{\circ} \mathrm{C}$. Filter paper disks $(\varnothing=6 \mathrm{~mm})$ containing $10 \mu \mathrm{L}$ of a solution $\left(5 \mathrm{mg} \mathrm{mL}^{-1}\right)$ of either compound $\mathbf{1}$ or $\mathbf{2}$ in ethyl acetate were applied to the surfaces of the PDA plates previously inoculated with a test microorganism (mycelial plug or surface inoculation). Pure ethyl acetate was used as the control. The plates were incubated at $28 \pm 2{ }^{\circ} \mathrm{C}$ for between 2 and 20 days, depending on the fungi growth rates. The inhibition zone diameter (including the disk diameter) was measured at the point of marked decrease in fungal density.

Minimum inhibitory concentration (MIC)

The minimum inhibitory concentration (MIC) assays against Aspergillus niger, Cladosporium sp. and Penicillium digitatum were adapted from the CLSI M38 method for antifungal susceptibility testing of filamentous fungi. ${ }^{16}$ Isolated colonies were suspended and diluted to yield final inocula of $10^{6} \mathrm{CFU} \mathrm{mL}^{-1}$. Tests were performed using sterile 96-well microplates, with addition to each well of $95 \mu \mathrm{L}$ of culture medium (RPMI 1640), $5 \mu \mathrm{L}$ of inoculum, and $100 \mu \mathrm{L}$ of a solution of either compound $\mathbf{1}$ or 2 in the culture medium (total volume of $200 \mu \mathrm{L}$ ). The final concentrations in the wells ranged from 4 to

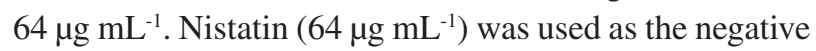
control and sodium chloride solution $(0.85 \% \mathrm{~m} / \mathrm{v})$ was the positive control. The plates were incubated for $48 \mathrm{~h}$ at $35 \pm 2{ }^{\circ} \mathrm{C}$. Fungal growth was evaluated visually, and the MIC was defined as the lowest concentration of the compound that inhibited growth. All experiments were performed in quintuplicate.

\section{Results and Discussion}

In a first trial, $C$. canadensis specimens collected in Brazil were extracted using dichloromethane, chloroform, and hexane, as described by Queiroz et al., ${ }^{7}$ in order to determine whether the compounds isolated from North American specimens were also present in specimens growing in Brazil. Using GC-MS analysis, it was possible to confirm that compounds $\mathbf{1}$ and $\mathbf{2}$ were present in both hexanic and chloroformic fractions. Compound $\mathbf{3}$ was also detected in both fractions, but in very small quantities, rendering its isolation impossible. The low concentrations of compound $\mathbf{3}$ in the extracts differed from the earlier findings of Queiroz et al., ${ }^{7}$ who isolated it in larger amounts from North American specimens. This was not unexpected, because the composition of $C$. canadensis essential oil can vary according to the collection site and the growth phase of the plant. ${ }^{17,18}$

The chloroform fraction, with fewer concomitant compounds, was submitted to preparative flash chromatography in order to isolate the analytes of interest. The NMR spectra of the isolated compounds $\mathbf{1}$ and $\mathbf{2}$ agreed with published data, except for the C-8 and C-9 
carbons of compound 1. For this compound, ${ }^{1} \mathrm{H}-{ }^{13} \mathrm{C}$ HSQC analysis (Figure S7, Supplementary Information section) revealed that the carbon at $\delta 21.8(\mathrm{C}-8)$ was correlated to the hydrogen at $\delta 2.43(\mathrm{H}-8)$, and that the carbon at $\delta 22.1$ (C-9) was correlated to the hydrogen at $\delta 1.62(\mathrm{H}-9)$, rather than the opposite, as reported by Rivera et al. ${ }^{13}$ These data are consistent with reports in the literature for the chemical shifts of carbons and hydrogens near triple bonds. ${ }^{19}$ For compound 2, the ${ }^{1} \mathrm{H}-{ }^{13} \mathrm{C}$ HSQC analysis confirmed the attributions available in the literature. ${ }^{14}$ To the best of our knowledge, these are the first 2D NMR experiments carried out for compounds $\mathbf{1}$ and $\mathbf{2}$.

\section{Optimization of the extraction using PHWE}

Temperature, extraction time, and the number of cycles are the main factors affecting PHWE efficiency and selectivity. ${ }^{20,21}$ Temperature affects the polarity of the extraction solvent and its capacity to penetrate into the matrix, altering its surface tension and viscosity. Furthermore, selection of a suitable temperature is essential to avoid degradation of thermolabile compounds and to prevent hydrolysis and oxidation reactions. ${ }^{20-22}$ Extractions at different temperatures $\left(70,90,100,110\right.$ and $\left.130{ }^{\circ} \mathrm{C}\right)$, maintaining a constant extraction time of 3 cycles of 20 min each, showed that the general extraction yield (the mass of purified extract per gram of plant material) increased significantly with temperature (Figure 2). The general extraction yield was $60 \mathrm{mg} \mathrm{g}^{-1}$ at $70{ }^{\circ} \mathrm{C}$, and increased nearly two-fold at $130{ }^{\circ} \mathrm{C}$, to $114 \mathrm{mg} \mathrm{g}^{-1}$. Nevertheless, the extraction at $100^{\circ} \mathrm{C}$ gave better yields of compounds 1 (1.55 $\left.\mathrm{mg} \mathrm{g}^{-1}\right)$ and $2\left(0.25 \mathrm{mg} \mathrm{g}^{-1}\right)$, compared to the other extraction temperatures evaluated (Figure 2).

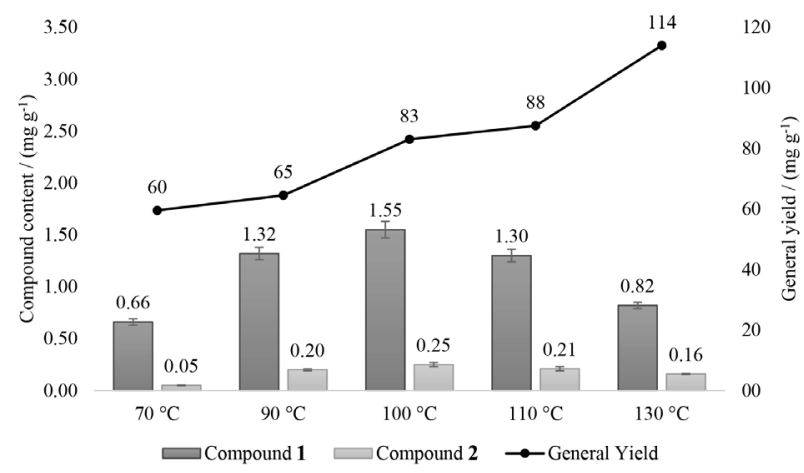

Figure 2. Compound yields and general yields for the purified extracts (ethyl acetate) during optimization of the extraction temperature.

Lower yields of these compounds were obtained at temperatures of 70 and $90{ }^{\circ} \mathrm{C}$, due to less significant reductions of the surface tension and viscosity of water, which hindered its ability to penetrate the matrix and extract the analytes. Above $100{ }^{\circ} \mathrm{C}$, although degradation products were not observed in the chromatograms, it is possible that some degradation of the analytes occurred and that the products were not extracted by partitioning with ethyl acetate.

In samples consisting of plant material, the limiting extraction steps are those involving diffusion processes and solubilization of the compounds. ${ }^{21}$ It is therefore expected that a longer extraction should provide higher efficiency. However, it is also possible that prolonged heating could lead to degradation of the compounds of interest. ${ }^{20}$ Extractions performed using different times per cycle $(1,5$, 10,20 and $30 \mathrm{~min}$ ), employing 3 extraction cycles at a fixed temperature of $100^{\circ} \mathrm{C}$, showed that the general extraction yield increased with the extraction time. The general extraction yield ranged from $64 \mathrm{mg} \mathrm{g}^{-1}$ (1 min per cycle) to $82 \mathrm{mg} \mathrm{g}^{-1}$ (20 min per cycle), an increase of approximately $29 \%$ in efficiency. However, extraction using 1 min cycles was more efficient for both analytes, yielding 1.91 and $0.31 \mathrm{mg} \mathrm{g}^{-1}$ of compound $\mathbf{1}$ and compound $\mathbf{2}$, respectively (Figure 3). Here again, it can be supposed that prolonged heating in longer extractions caused degradation of the analytes prior to their elution from the extraction cell. However, no degradation products were found in the chromatograms to confirm this hypothesis.

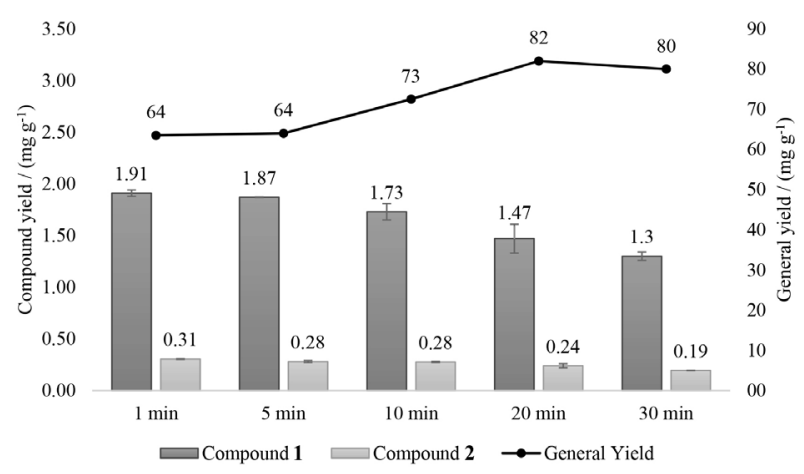

Figure 3. Compound yields and general yields for the purified extracts (ethyl acetate) during optimization of the extraction time per cycle.

In static mode, the efficiency of PHWE depends on the partition coefficient and the solubility of the compounds at the selected temperature. However, extractions may be incomplete due to the limited volume of solvent in the extraction cell. One way to minimize this problem is to use a greater number of extraction cycles..$^{20}$ On the other hand, the use of many extraction cycles results in a more time- and solvent-consuming procedure. Therefore, the percentages of compounds $\mathbf{1}$ and $\mathbf{2}$ were evaluated in each extraction cycle, using a total of 4 cycles (Figure 4).

For compound 1, the second cycle shows the highest yield, while the fourth (final) cycle was, on average, only 


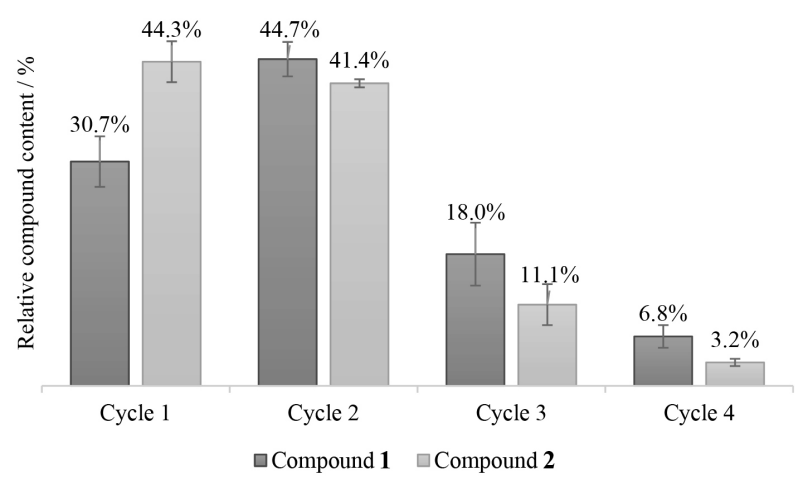

Figure 4. Compound contents in the purified extracts (ethyl acetate) during optimization of the number of extraction cycles.

responsible for $6.8 \%$ of the total amount of the substance present in the purified extract. For compound 2, the first and second cycles showed comparable average yields (44.3 and $41.4 \%$, respectively), while the fourth cycle was responsible for $3.2 \%$, on average, of the total amount of the substance in the purified extract. Since the extractions of these two compounds in the fourth cycle were low, compared to the other cycles, the use of four extraction cycles was considered sufficient. Additional cycles would increase the aqueous extract volume and would require greater amounts of ethyl acetate for partitioning, which would be disadvantageous.

Once the extraction had been optimized $\left(100{ }^{\circ} \mathrm{C}\right.$, 4 cycles of $1 \mathrm{~min}$ each), the repeatability of the procedure was evaluated by means of the inter-day and intra-day precisions, with the results expressed as the relative standard deviations (RSD) (Table 1). The RSD values were below $6.7 \%$, which was considered acceptable for the desired application.

These results reinforced the viability and efficiency of PHWE for the extraction of bioactive compounds from C. canadensis. The ability to obtain an aqueous extract of these compounds represents an advance in the direct
Table 1. Precision of the extraction procedure, expressed as the relative standard deviation (RSD)

\begin{tabular}{lcc}
\hline \multirow{2}{*}{ Compound } & \multicolumn{2}{c}{ RSD / \% } \\
\cline { 2 - 3 } & Intra-day $(\mathrm{n}=5)$ & Inter-day $(\mathrm{n}=8)$ \\
\hline $\mathbf{1}$ & 6.3 & 5.7 \\
$\mathbf{2}$ & 5.8 & 6.7 \\
\hline
\end{tabular}

application of plant extracts in postharvest treatments, because aqueous extracts are less hazardous to use than organic (chlorinated) solvent extracts.

\section{Disk diffusion assays against postharvest fungi}

Compounds 1 and $\mathbf{2}$ showed similar antifungal activities. As shown in Table 2, both inhibited growth of Aspergillus niger (CMAA 1132) and Cladosporium sp. (CMAA 1136). For the later, however, compound 1 was more active than compound $\mathbf{2}$. Additionally, only compound 1 significantly inhibited the growth of Penicillium digitatum (CMAA 1190). This assay was used as a screening method to determine which fungi would be submitted to the MIC assays.

\section{Minimum inhibitory concentration (MIC)}

The purpose of this test was to determine the minimum amount of each compound that caused inhibition of fungal growth. Given this information, subsequent tests involving the application of aqueous extracts of $C$. canadensis to fruits could be carried out using appropriate concentrations of the compounds. Compound $\mathbf{1}$ was most active against the fungus Penicillium digitatum $\left(32 \mathrm{mg} \mathrm{L}^{-1}\right)$, while compound $\mathbf{2}$ showed greater activity against Aspergillus niger $\left(32 \mathrm{mg} \mathrm{L}^{-1}\right)$. The MIC results are listed in Table 2.

Table 2. Fungal species evaluated and their corresponding codes, the fruits from which they were isolated, inhibition scores for each compound (cpd.), and minimum inhibitory concentrations (MIC)

\begin{tabular}{|c|c|c|c|c|c|c|}
\hline \multirow{2}{*}{ Code } & \multirow{2}{*}{ Fungus } & \multirow{2}{*}{ Fruit } & \multicolumn{2}{|c|}{ Inhibition } & \multicolumn{2}{|c|}{$\mathrm{MIC} /\left(\mu \mathrm{g} \mathrm{mL}^{-1}\right)$} \\
\hline & & & Cpd. 1 & Cpd. 2 & Cpd. 1 & Cpd. 2 \\
\hline CMAA 1129 & Colletotrichum gloeosporioides & mango & - & - & n.a. & n.a. \\
\hline CMAA 1130 & Alternaria alternata & mango & - & - & n.a. & n.a. \\
\hline CMAA 1131 & Lasiodiplodia theobromae & mango & - & - & n.a. & n.a. \\
\hline CMAA 1133 & Botryosphaeria dothidea & mango & - & - & n.a. & n.a. \\
\hline CMAA 1132 & Aspergillus niger & grape & + & + & 64 & 32 \\
\hline CMAA 1135 & Alternaria alternata & grape & - & - & n.a. & n.a. \\
\hline CMAA 1136 & Cladosporium sp. & grape & ++ & + & 64 & 64 \\
\hline CMAA 1134 & Fusarium pallidoroseum & melon & - & - & n.a. & n.a. \\
\hline CMAA 1137 & Alternaria alternata & melon & - & - & n.a. & n.a. \\
\hline CMAA 1190 & Penicillium digitatum & orange & + & - & 32 & 64 \\
\hline
\end{tabular}

Score: halo $<15 \mathrm{~mm}(+)$; halo $\geq 15 \mathrm{~mm}(++)$; no inhibition $(-)$. 
The results of this test were promising, because the susceptible fungi are common postharvest pathogens of fruits and vegetables. ${ }^{23}$ Aspergillus niger causes black mold and other rots in citrus fruits, grapes, figs, peaches, mangoes, apples and strawberries. Moreover, in Brazil it is responsible (amongst other fungi) for the contamination of grapes and wines with ochratoxin $\mathrm{A},{ }^{24}$ a mycotoxin with nephrotoxic, teratogenic, hepatotoxic and immunotoxic effects in animals and possibly humans, which is classified as a possible carcinogen. ${ }^{25,26}$ The Cladosporium genus causes rots in capsicum, berries, tomatoes and eggplants. ${ }^{23}$ Lastly, Penicillium digitatum is the causative agent of green mold in citrus fruits and is responsible for 60 to $80 \%$ of losses during the storage period. ${ }^{27}$

\section{Conclusions}

The allelopathic weed Conyza canadensis proved to be a promising source of antifungal compounds with potential use in the treatment of postharvest diseases of fruits and vegetables. The compounds 4Z-lachnophyllum lactone and 4Z,8Z-matricaria lactone, both isolated and identified by mass spectrometry and NMR analysis in this work, demonstrated significant antifungal activity against Aspergillus niger, Penicillium digitatum and another fungus of the Cladosporium genus. Aside the traditional extraction method employing organic solvents, it was possible to extract these compounds from the aerial parts of Conyza canadensis by employing pressurized hot water as solvent. This green extraction method was optimized and had its reproducibility assessed, proving to be a viable alternative to obtain the referred antifungal compounds with an adequate yield. Thus, it could be possible to apply the crude aqueous extracts on harvested fruits and vegetables to prevent or delay the appearance of postharvest diseases, prolonging their shelf life and reducing production losses.

\section{Supplementary Information}

NMR spectra $\left({ }^{1} \mathrm{H},{ }^{13} \mathrm{C}\right.$ and $\left.\mathrm{HSQC}\right)$ and attributions for compounds $\mathbf{1}$ and $\mathbf{2}$, together with the chromatography and NMR operational conditions, are available free of charge at http://jbcs.sbq.org.br as a PDF file.

\section{Acknowledgments}

We thank Prof Daniel Terao for his assistance with the selection of the postharvest disease fungi species, Prof Marta Camargo de Assis for her help with plant collection and voucher deposition, and Rodrigo Castanha and Dr Suikinai Nobre dos Santos for technical assistance. We acknowledge the financial support provided by CNPq (grant number 482675/2012-8) and FAPESP (grant numbers 2012/017670 and 2013/09543-7).

\section{References}

1. Sivakumar, D.; Bautista-Baños, S.; Crop Prot. 2014, 64, 27.

2. Prusky, D.; Food Secur. 2011, 3, 463.

3. Liu, J.; Sui, Y.; Wisniewski, M.; Droby, S.; Liu, Y.; Int. J. Food Microbiol. 2013, 167, 153.

4. http://www.epa.gov/ingredients-used-pesticide-products/whatare-biopesticides, accessed in July 2016.

5. Dayan, F. E.; Cantrell, C. L.; Duke, S. O.; Bioorg. Med. Chem. 2009, 17, 4022.

6. Nunes, C. A.; Eur. J. Plant Pathol. 2011, 133, 181.

7. Queiroz, S. C.; Cantrell, C. L.; Duke, S. O.; Wedge, D. E.; Nandula, V. K.; Moraes, R. M.; Cerdeira, A. L.; J. Agric. Food Chem. 2012, 60, 5893.

8. Duke, S. O.; Dayan, F. E.; Rimando, A. M.; Schrader, K. K.; Aliotta, G.; Oliva, A.; Romagni, J. G.; Weed Sci. 2002, 50, 138.

9. Curini, M.; Bianchi, A.; Epifano, F.; Bruni, R.; Chem. Nat. Compd. 2003, 39, 191.

10. Franzener, G.; Martinez-Franzener, A. S.; Stangarlin, J. R.; Czepak, M. P.; Schwan-estrada, K. R. F.; Eugênia, M.; Cruz, S.; Semina: Cienc. Agrar. 2007, 28, 29.

11. Veres, K.; Csupor-Löffler, B.; Lázár, A.; Hohmann, J.; Sci. World J. 2012, 2012, ID 489646.

12. Meepagala, K. M.; Sturtz, G.; Wise, D.; Wedge, D. E.; Pest Manag. Sci. 2002, 58, 1043.

13. Rivera, P.; Arancibia, L.; Castillo, M.; J. Nat. Prod. 1989, 52, 433.

14. Csupor-Loffler, B.; Hajdu, Z.; Zupko, I.; Molnar, J.; Forgo, P.; Vasas, A.; Kele, Z.; Hohmann, J.; Planta Med. 2011, 77, 1183.

15. Bär, B.; Schultze, W.; Planta Med. 1996, 62, 329.

16. The Clinical and Laboratory Standards Institute (CLSI); M38-A: Reference Method for Broth Dilution Antifungal Susceptibility Testing of Filamentous Fungi; Approved Standard; CLSI: Wayne, USA, 2002.

17. Tzakou, O.; Vagias, C.; Gani, A.; Yannitsaros, A.; Flavour Fragrance J. 2005, 20, 425.

18. Lis, A.; Piggott, J. R.; Góra, J.; Flavour Fragrance J. 2003, 18, 364.

19. Pretsch, E.; Bühlmann, P.; Badertscher, M.; Structure Determination of Organic Compounds-Tables of Spectral Data, $4^{\text {th }}$ ed.; Springer: Berlin, Germany, 2009.

20. Teo, C. C.; Tan, S. N.; Yong, J. W.; Hew, C. S.; Ong, E. S.; J. Chromatogr. A 2010, 1217, 2484.

21. Mustafa, A.; Turner, C.; Anal. Chim. Acta 2011, 703, 8.

22. Heng, M. Y.; Tan, S. N.; Yong, J. W. H.; Ong, E. S.; TrAC, Trends Anal. Chem. 2013, 50, 1. 
23. Coates, L.; Johnson, G. In Plant Pathogens and Plant Diseases, $1^{\text {st }}$ ed.; Brown, J. F.; Ogle, H. J., eds.; Rockvale Publications: Armidale, Australia, 1997, ch. 33.

24. Varga, J.; Houbraken, J.; Samson, R. A.; Frisvad, J. C. In Mycotoxins in Fruits and Vegetables; Barkai-Golan, R.; Paster, N., eds.; Academic Press: Amsterdam, 2008, ch. 9.

25. International Agency for Research on Cancer (IARC); IARC Monographs on the Evaluation of Carcinogenic Risks to Humans; Some Naturally Occurring Substances: Food Items and Constituents, Heterocyclic Aromatic Amines and Mycotoxins, IARC: Lyon, France, 1993.
26. Pozo-Bayon, M. A.; Monagas, M.; Bartolome, B.; MorenoArribas, M. V.; Crit. Rev. Food Sci. Nutr. 2012, 52, 31.

27. Ballester, A. R.; Lafuente, M. T.; Forment, J.; Gadea, J.; de Vos, R. C.; Bovy, A. G.; Gonzalez-Candelas, L.; Mol. Plant Pathol. 2011, 12, 879 .

Submitted: May 27, 2016

Published online: August 8, 2016

FAPESP has sponsored the publication of this article. 